\title{
Prevalence of diabetic peripheral neuropathy and its relation to glycaemic control and potential risk factors: the EURODIAB IDDM Complications Study
}

\author{
S. Tesfaye ${ }^{1}$, L. K. Stevens ${ }^{2}$, J. M.Stephenson ${ }^{2}$, J.H.Fuller ${ }^{2}$, M.Plater ${ }^{3}$, C. Ionescu-Tirgoviste ${ }^{4}$, A. Nuber ${ }^{5}$ G. Pozza $^{6}$, \\ J.D. Ward ${ }^{3}$ and the EURODIAB IDDM Study Group* \\ ${ }^{1}$ Diabetes Unit, Royal Liverpool University Hospital, Liverpool, UK \\ ${ }^{2}$ EURODIAB, Department of Epidemiology and Public Health, University College London, London, UK \\ ${ }^{3}$ Diabetes Research Unit, Royal Hallamshire Hospital, Sheffield, UK \\ ${ }^{4}$ Clinic of Diabetes, Institute "N. Paulescu", Bucharest, Romania \\ ${ }^{5}$ City Hospital Schwabing, Munich, Germany \\ ${ }^{6}$ Ospedale San Raffaele, Milan, Italy
}

Summary The EURODIAB IDDM Complications Study involved the examination of 3250 randomly selected insulin-dependent diabetic patients, from 31 centres in 16 European countries. Part of the examination included an assessment of neurological function including neuropathic symptoms and physical signs, vibration perception threshold, tests of autonomic function and the prevalence of impotence. The prevalence of diabetic neuropathy across Europe was $28 \%$ with no significant geographical differences. Significant correlations were observed between the presence of diabetic peripheral neuropathy with age $(p<0.05)$, duration of diabetes $(p<0.001)$, quality of metabolic control $(p<0.001)$, height $(p<0.01)$, the presence of background or proliferative diabetic retinopathy $(p<0.01)$, cigarette smoking $(p<0.001)$, high-density lipoprotein cholesterol $(p<0.001)$ and the presence of cardiovascular disease $(p<0.05)$, thus confirming previous associations. New associations have been identified from this study - namely with elevated diastolic blood pressure $(p<0.05)$, the presence of severe ketoacidosis $(p<0.001)$, an increase in the levels of fasting triglyceride $(p<0.001)$, and the presence of microalbuminuria $(p<0.01)$. All the data were adjusted for age, duration of diabetes and $\mathrm{HbA}_{1 \mathrm{c}}$. Although alcohol intake correlated with absence of leg reflexes and autonomic dysfunction, there was no overall association of alcohol consumption and neuropathy. The reported problems of impotence were extremely variable between centres, suggesting many cultural and attitudinal differences in the collection of such information in different European countries. In conclusion, this study has identified previously known and new potential risk factors for the development of diabetic peripheral neuropathy. [Diabetologia (1996) 39: 1377-1384]

Keywords Insulin-dependent diabetes mellitus, diabetic neuropathy, prevalence, glycaemic control, microalbuminuria, impotence, epidemiology.
No diabetes physician would question the fact that problems relating to nerve damage in diabetes mellitus are extremely common and result in much patient morbidity and unhappiness [1]. However, as the cause and natural history of diabetic peripheral

Received: 14 December 1995 and in revised form: 27 June 1996

Corresponding author: Dr. S. Tesfaye, Diabetes Unit, Link 7C, Royal Liverpool University Hospital, Prescot Street, Liverpool L7 8XP, UK

Abbreviations: IDDM, Insulin-dependent diabetes; NIDDM, non-insulin-dependent diabetes; gamma GT, gamma glutamyl transferase.

* See Acknowledgements neuropathy remain unknown, attempts at defining minimal criteria for the presence of neuropathy have proved difficult [2]. This is probably the most important reason for the widely varied estimates of the prevalence of diabetic peripheral neuropathy. Other factors include differing patient selection criteria, the small size of cohorts and the employment of different diagnostic tests. Some studies have used the presence of neuropathic symptoms [3] alone for the diagnosis of neuropathy while others have used both symptoms and signs of neuropathy as minimal criteria for diagnosis [4, 5]. The San Antonio Conference on Diabetic Neuropathy [6] recommended that for full classification of diabetic neuropathy, at least one measure from each of the following categories need 
to be assessed: neuropathic symptoms, clinical examination, electrodiagnostic tests, quantitative sensory tests and autonomic function tests. With this in mind, the present study was conducted to determine the prevalence of diabetic neuropathy and its relation to known risk factors such as age, duration of diabetes and glycaemic control, and other potential risk factors, in a cross-sectional study involving over 3000 randomly selected insulin-dependent diabetic (IDDM) subjects, from 31 centres across Europe.

The aim of the neuropathy section of the EURODIAB IDDM Complications Study [7] was to measure the prevalence of diabetic peripheral neuropathy using measures that would be meaningful to clinicians, i.e. reasonable clinical and neurophysiological measures to be applied to large numbers of patients with a high degree of accuracy. Moreover, recognition of potential risk factors may provide possible pathogenetic mechanisms for the development of neuropathy.

Studying patients across a wide geographical area presented the opportunity to identify any regional differences which might give clues to environmental or other risk factors for the development of diabetic neuropathy. The opportunity was also taken to estimate the prevalence of diabetic impotence.

\section{Subjects and methods}

Three thousand two hundred and fifty patients were studied (1668 males and 1582 females, mean age \pm SD $32.7 \pm$ 10.2 years, mean duration of diabetes $14.7 \pm 9.3$ years, mean $\mathrm{HbA}_{1 \mathrm{c}}, 6.7 \pm 1.9 \%$ ) [7]. Subjects with IDDM were randomly selected in a stratified manner from 31 diabetes clinic populations around Europe [7]. Patient selection criteria and methods have been described in detail in a recent publication [7].

In all subjects $\mathrm{HbA}_{1 \mathrm{c}}$, gamma glutamyl transferase (gamma GT), lipid profile and urinary albumin excretion rate were measured, the latter being derived from a single 24-h urine collection [7]. The daily intake of alcohol (g/day) was calculated from a detailed dietary record over 3 days. The presence and severity of diabetic retinopathy was assessed from centrally graded retinal photographs (two fields per eye) taken with a wide-angle camera [8]. Retinopathy was classified as background or proliferative. Proliferative retinopathy was defined as any new vessels, fibrous proliferations, pre-retinal haemorrhage, vitreous haemorrhage or photocoagulation scars.

Severe hypoglycaemia was defined as any episode severe enough to require the help of another person. Severe ketoacidosis was defined as an episode requiring hospital admission. Subjects were asked how many such episodes they had over the last 12 months.

Cardiovascular disease was defined either as the presence of a past history of cardiovascular disease (previous myocardial infarction, angina, coronary bypass grafting, stroke) or abnormal 12-lead electrocardiogram (classified by two observers according to the Minnesota Code).

The assessment of neuropathic symptoms and signs, measurement of vibration perception threshold and autonomic function constituted a protocol similar in detail to a number of protocols recently published $[4,5,9]$, in order to standardise an approach to the assessment and definition of diabetic neuropathy. For the sake of comparison with other similar protocols, details are provided of the various measures which were carried out.

Assessment of neuropathic symptoms [10]. The presence of the following symptoms over the previous 6 months was ascertained: a) numbness or dead feeling in the feet; b) prickling sensation in the feet; c) deep or burning pains in the legs; d) unusual difficulty in climbing stairs; e) difficulty controlling the bladder and f) any trouble with nocturnal diarrhoea. In addition male patients were asked questions regarding impotence over the previous 6 months: a) any problems with sexual intercourse; b) any problems with obtaining an erection; c) any problems with sustaining an erection and d) spontaneous erections at night or in the morning.

Neurological examination. Ankle and knee reflexes were performed, with reinforcement if necessary.

Vibration perception threshold assessment. This was measured by centrally calibrated biothesiometers (Biomedical, Newbury, Ohio, USA) [11]. Three readings were taken up to the nearest unit, on the right big toe and right medial malleolus, and their average used for analysis.

Autonomic function assessment. Autonomic function was assessed by testing two cardiovascular reflex responses: change in heart rate, and change in systolic blood pressure on standing up measured by a Hawksley random zero sphygmomanometer after resting horizontally for at least $5 \mathrm{~min}$. The ratio of the longest electrocardiogram R-R interval between 28th and 32 nd beats following standing to the shortest interval between the 13 th and 17 th beats was calculated by a single observer.

Definition of diabetic neuropathy. Diabetic neuropathy was diagnosed if abnormalities were found in two or more of the above described criteria, i.e. 1) the presence of one or more symptoms; 2) absence of two or more ankle or knee reflexes; 3 ) vibration perception threshold which was abnormal relating to age-related measures [12] and 4) abnormal autonomic function assessed using Ewing's definitons [13] of postural hypotension with a fall in systolic blood pressure of $30 \mathrm{~mm} \mathrm{Hg}$ or more, and/or loss of heart rate variability $(\mathrm{R}-\mathrm{R}$ ratio $<1)$.

\section{Statistical analysis}

Rates of neuropathy were directly standardised to the age, duration of diabetes and $\mathrm{HbA}_{1 \mathrm{c}}$ distributions of the whole sample. To assess the association between neuropathy and potential risk factors, continuous variables were grouped into quartiles and standardised relative risks of neuropathy were calculated, comparing the standardised rates of neuropathy in each quartile relative to that of the lowest quartile. For other diabetic complications standardised relative risks of neuropathy were calculated for those with complications relative to those without, and for smoking, relative risk of neuropathy was calculated for current smokers and ex-smokers relative to nonsmokers. Differences and trends in standardised relative risk were assessed using the extended Mantel Haenszel chi-square test. Backward stepwise logistics regression was used to assess the independent effect of significant risk factors on neuropathy and variables entered into the initial model were those having a significant association with neuropathy $(p<0.05)$ in previous analysis. The criteria for a risk factor to leave the model was 


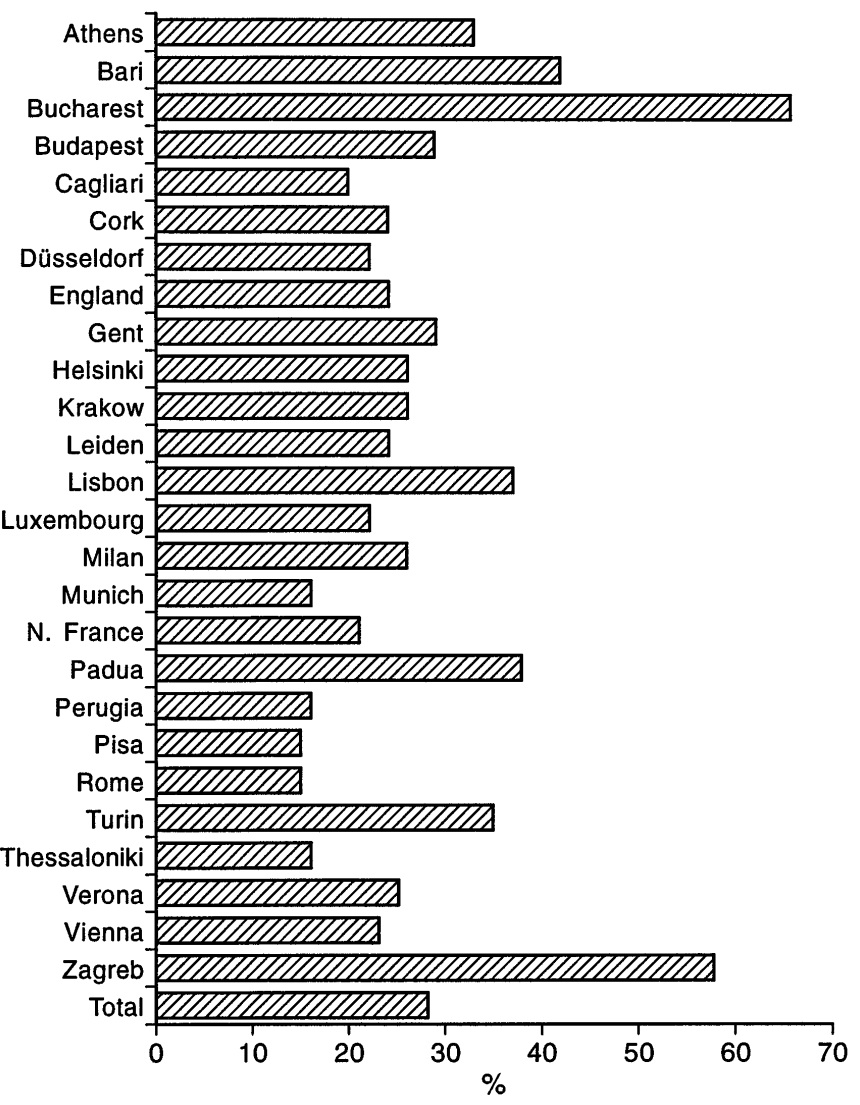

Fig. 1. Between centre variation in diabetic neuropathy

$p>0.05$. All analyses including serum triglyceride level excluded patients that were non-fasting, and because this resulted in skewed distribution, serum triglyceride level was log transformed for the regression analysis. Standardised relative risks were calculated, for a continuous variable, as the relative risk of neuropathy associated with an increase of one standard deviation. For a categorical variable it was the risk of neuropathy associated with the presence of the risk factor relative to the risk when it was absent.

\section{Results}

The overall prevalence of diabetic peripheral neuropathy was $28 \%$, with no difference according to sex. Figure 1 shows the prevalence of diabetic peripheral neuropathy in each centre. Although five centres had prevalences in excess of $35 \%$, there were no significant differences in the prevalence of neuropathy between the other centres. The following parameters were observed to see if there were significant associations with diabetic neuropathy:

Age, duration of diabetes and glycaemic control (Table 1). There were significant trends in the prevalence of diabetic peripheral neuropathy with increasing age $(p<0.05)$, duration of diabetes $(p<0.001)$ and $\mathrm{HbA}_{1 \mathrm{c}}$ $(p<0.001)$. Adjustments were made for age, duration of diabetes and $\mathrm{HbA}_{1 \mathrm{c}}$ as appropriate, as shown in
Table 1. Frequencies (\%) of diabetic neuropathy by age, duration and glycaemic control

\begin{tabular}{lclll}
\hline & Total & & \\
\cline { 2 - 4 } & $n$ & $\begin{array}{l}\text { No. with } \\
\text { neuropathy }\end{array}$ & $\%$ & $\begin{array}{l}\text { Adjusted } \\
(95 \% \mathrm{CI}) \\
\text { rate }^{\mathrm{a}}\end{array}$ \\
\hline $\begin{array}{llll}\text { Age (years) } \\
\text { 15-29 }\end{array}$ & 1348 & 262 & 19 & $21(18-24)$ \\
$30-44$ & 1238 & 348 & 28 & $29(25-32)$ \\
$45-61$ & 410 & 232 & 57 & $35(24-46)$ \\
& & & & $p<0.05$ \\
Diabetes duration (years) & & 12 & $11(9-13)$ \\
$<7$ & 817 & 98 & 22 & $23(18-28)$ \\
$8-14$ & 872 & 192 & 42 & $38(34-42)$ \\
15 & 1305 & 549 & & $p<0.001$ \\
& & & 15 & $17(14-20)$ \\
HbA & & & 26 & $24(21-27)$ \\
$<5.4$ & 719 & 111 & 30 & $29(25-33)$ \\
$5.4-6.4$ & 764 & 200 & 40 & $41(36-46)$ \\
$6.5-7.7$ & 739 & 225 & & $p<0.001$ \\
$7.8+$ & 761 & 301 & &
\end{tabular}

${ }^{a}$ Rates in each age category were adjusted for duration and $\mathrm{HbA}_{1 \mathrm{c}}$. Rates for each duration category are adjusted for age and $\mathrm{HbA}_{1 \mathrm{c}}$. Rates for each $\mathrm{HbA}_{1 \mathrm{c}}$ category were adjusted for age and duration

Table 1. Age at diagnosis of IDDM was not related to the prevalence of neuropathy.

Height, weight, body mass index, blood pressure and smoking (Table 2). Significant trends of increasing prevalence of diabetic peripheral neuropathy were only observed with increasing height $(p<0.01)$ and diastolic blood pressure $(p<0.05)$ when data was adjusted for age, duration of diabetes and $\mathrm{HbA}_{1 \mathrm{c}}$. Current smoking status was also significantly associated with the prevalence of diabetic neuropathy $(p<0.001)$.

Lipids and lipoproteins (Table 3). Although significant trends in increasing prevalence of diabetic neuropathy were observed with an increase in lipid and lipoprotein levels, only reduced HDL-cholesterol $(p<0.001)$ and raised fasting triglyceride $(p<0.001)$ levels were found to have significant associations with neuropathy when the data were adjusted for age, duration of diabetes and $\mathrm{HbA}_{1 \mathrm{c}}$.

Acute diabetic complications (Fig. 2). Only the presence of severe ketoacidocis was related to an increase in the relative risk of diabetic neuropathy $(p<0.001)$.

Chronic diabetic complications (Fig.3). Significant association was found between the prevalence of diabetic neuropathy and the presence of cardiovascular disease $(p<0.05)$. There was also a significant $(p<0.01)$ trend in the increase in the relative risk for the presence of diabetic neuropathy with an increase 
Table 2. Frequencies (\%) of diabetic neuropathy and its association with blood pressure, body mass index, weight, height and smoking

\begin{tabular}{|c|c|c|c|}
\hline & $\begin{array}{l}\text { Neuropathy } \\
\text { no }(\%)\end{array}$ & $\begin{array}{l}\text { Crude relative } \\
\text { risk }(95 \% \mathrm{CI}) \\
\text { of neuropathy }\end{array}$ & $\begin{array}{l}{ }^{\text {a}} \text { Adjusted } \\
\text { relative risk } \\
(95 \% \mathrm{CI}) \text { of } \\
\text { neuropathy }\end{array}$ \\
\hline \multicolumn{4}{|c|}{ Systolic blood pressure $(\mathrm{mm} \mu \mathrm{g})$} \\
\hline$<120$ & $352(24)$ & 1 & 1 \\
\hline $120-129$ & $183(27)$ & $1.15(0.99,1.34)$ & $1.00(0.83,1.20)$ \\
\hline 130-139 & $139(33)$ & $1.39(1.18,1.64)$ & $1.10(0.90,1.35)$ \\
\hline $140+0$ & $168(41)$ & $\begin{array}{l}1.71(1.47,1.98) \\
p<0.001^{\mathrm{b}}\end{array}$ & $0.99(0.81,1.22)$ \\
\hline \multicolumn{4}{|c|}{ Diastolic blood pressure $(\mathrm{mm} \mu \mathrm{g})$} \\
\hline$\leq 68$ & $12(27)$ & 1 & 1 \\
\hline $69-75$ & $189(23)$ & $0.86(0.73,1.02)$ & $0.97(0.79,1.18)$ \\
\hline $76-83$ & $202(28)$ & $1.01(0.86,1.19)$ & $1.06(0.88,1.29)$ \\
\hline $84+$ & $236(35)$ & $\begin{array}{l}1.29(1.11,1.51) \\
p<0.001^{\mathrm{b}}\end{array}$ & $\begin{array}{l}1.26(1.04,1.51) \\
p<0.05^{\mathrm{b}}\end{array}$ \\
\hline \multicolumn{4}{|c|}{ Body mass index $\left(\mathrm{kg} / \mathrm{m}^{2}\right)$} \\
\hline$<21.50$ & $192(26)$ & 1 & 1 \\
\hline $21.50-23.22$ & $188(25)$ & $0.96(0.81,1.14)$ & $0.92(0.75,1.13)$ \\
\hline $23.23-25.26$ & $205(27)$ & $1.03(0.87,1.22)$ & $0.90(0.74,1.10)$ \\
\hline $25.27+$ & $252(34)$ & $\begin{array}{l}1.29(1.10,1.51) \\
p<0.001^{\mathrm{b}}\end{array}$ & $1.04(0.86,1.26)$ \\
\hline \multicolumn{4}{|l|}{ Weight $(\mathrm{kg})$} \\
\hline $\begin{array}{l}\leq 59 \\
60-66\end{array}$ & $\begin{array}{l}204(27) \\
196(26)\end{array}$ & $\begin{array}{l}1 \\
0.98(0.83,1.16)\end{array}$ & $\begin{array}{l}1 \\
0.96(0.79,1.18)\end{array}$ \\
\hline $67-74$ & $194(26)$ & $0.95(0.80,1.13)$ & $0.99(0.81,1.21)$ \\
\hline $75+$ & $248(34)$ & $\begin{array}{l}1.25(1.07,1.46) \\
p<0.05^{\mathrm{b}}\end{array}$ & $\begin{array}{l}1.25(1.04,1.51) \\
p<0.05^{\mathrm{b}}\end{array}$ \\
\hline \multicolumn{4}{|l|}{ Height $(\mathrm{cm})$} \\
\hline$\leq 162$ & $230(28)$ & 11 & \\
\hline $163-169$ & $205(27)$ & $0.95(0.81,1.12)$ & $1.05(0.87,1.27)$ \\
\hline $170-175$ & $199(29)$ & $1.02(0.87,1.20)$ & $1.21(1.00,1.47)$ \\
\hline $176+$ & $208(28)$ & $1.00(0.85,1.17)$ & $\begin{array}{l}1.32(1.09,1.60) \\
p<0.01^{\mathrm{b}}\end{array}$ \\
\hline \multicolumn{4}{|l|}{ Smoking } \\
\hline Non- & $355(24)$ & 1 & 1 \\
\hline Ex- & $186(35)$ & $\begin{array}{l}1.45(1.25,1.68) \\
p<0.05^{\mathrm{c}}\end{array}$ & $1.19(1.00,1.43)$ \\
\hline Current & $297(31)$ & $\begin{array}{l}1.30(1.14,1.48) \\
p<0.05^{\mathrm{c}}\end{array}$ & $\begin{array}{l}1.33(1.14,1.56) \\
p<0.001^{\mathrm{c}}\end{array}$ \\
\hline
\end{tabular}

$\overline{\mathrm{a}}$ Adjusted for age, duration and $\mathrm{HbA}_{1 \mathrm{c}}$; ${ }^{\mathrm{b}}$ testing for trend;

${ }^{c}$ testing for difference to non-smoking

in the progression of both retinopathy and albumin excretion.

Alcohol consumption. There was no significant association between alcohol consumption and diabetic neuropathy. However, an increase in alcohol intake did relate to autonomic dysfunction $(p<0.01)$, absence of leg reflexes $(p<0.01)$ and a rise in gamma GT.

Impotence. A wide range of responses between study centres led to rather unsatisfactory data in this particular part of the study (problems with intercourse, 2$35 \%$; problems with erection, $3-85 \%$; problems sustaining erection, $2-83 \%$; presence of spontaneous morning erections, $23-84 \%$ ).
Table 3. Association of diabetic neuropathy with lipids and liproproteins

\begin{tabular}{|c|c|c|c|}
\hline & $\begin{array}{l}\text { Crude rate of } \\
\text { neuropathy } \\
n(\%)\end{array}$ & $\begin{array}{l}\text { Relative risk } \\
(95 \% \mathrm{CI}) \\
\text { of neuropathy }\end{array}$ & $\begin{array}{l}\text { a Adjusted relative } \\
\text { risk }(95 \% \mathrm{CI}) \\
\text { neuropathy }\end{array}$ \\
\hline \multicolumn{4}{|c|}{ Total cholesterol $(\mathrm{mmol} / \mathrm{l})$} \\
\hline$\leq 4.55$ & $168(23)$ & 1 & 1 \\
\hline $4.56-5.23$ & $177(24)$ & $1.04(0.87,1.26)$ & $0.89(0.72,1.10)$ \\
\hline $5.24-5.96$ & $205(28)$ & $1.23(1.03,1.46)$ & $0.90(0.73,1.11)$ \\
\hline $5.97+$ & $282(39)$ & $\begin{array}{l}1.71(1.46,2.01) \\
p<0.001\end{array}$ & $1.03(0.84,1.26)$ \\
\hline \multicolumn{4}{|c|}{ HDL-cholesterol $(\mathrm{mmol} / \mathrm{l})$} \\
\hline$\leq 1.17$ & $259(36)$ & 1 & 1 \\
\hline $1.18-1.43$ & $183(25)$ & $0.69(0.59,0.81)$ & $0.73(0.60,0.88)$ \\
\hline $1.44-1.71$ & $186(25)$ & $0.71(0.61,0.84)$ & $0.76(0.63,0.92)$ \\
\hline $1.72+$ & $179(25)$ & $\begin{array}{l}0.71(0.61,0.84) \\
p<0.001\end{array}$ & $\begin{array}{l}0.67(0.55,0.81) \\
p<0.001\end{array}$ \\
\hline \multicolumn{4}{|c|}{ LDL-cholesterol $(\mathrm{mmol} / \mathrm{l})$} \\
\hline$\leq 2.69$ & $114(23)$ & 1 & 1 \\
\hline $2.70-3.25$ & $120(24)$ & $1.04(0.83,1.30)$ & $0.87(0.67,1.12)$ \\
\hline $3.26-3.92$ & $128(25)$ & $1.08(0.86,1.34)$ & $0.86(0.67,1.11)$ \\
\hline $3.93+$ & $184(37)$ & $\begin{array}{l}1.59(1.31,1.94) \\
p<0.001\end{array}$ & $0.95(0.74,1.21)$ \\
\hline \multicolumn{4}{|c|}{ Fasting triglyceride $(\mathrm{mmol} / \mathrm{l})$} \\
\hline$\leq 0.71$ & $122(16)$ & 1 & 1 \\
\hline $0.72-0.93$ & $168(22)$ & $1.32(1.02,1.70)$ & $1.12(0.84,1.49)$ \\
\hline $0.94-1.35$ & $213(29)$ & $1.79(1.41,2.27)$ & $1.35(1.03,1.78)$ \\
\hline $1.36+$ & $329(46)$ & $\begin{array}{l}2.72(2.19,3.38) \\
p<0.001\end{array}$ & $\begin{array}{l}1.97(1.52,2.56) \\
p<0.001\end{array}$ \\
\hline \multicolumn{4}{|c|}{ Total: HDL (ratio) } \\
\hline$\leq 2.93$ & $157(22)$ & 1 & 1 \\
\hline $2.94-3.59$ & $174(24)$ & $1.11(0.91,1.34)$ & $1.05(0.84,1.30)$ \\
\hline $3.60-4.47$ & $198(27)$ & $1.25(1.04,1.50)$ & $1.11(0.90,1.37)$ \\
\hline $4.48+$ & $278(39)$ & $\begin{array}{l}1.79(1.52,2.11) \\
p<0.001\end{array}$ & $1.40(1.15,1.71)$ \\
\hline
\end{tabular}

${ }^{a}$ Adjusted for age, duration and $\mathrm{HbA}_{1 \mathrm{c}}$

Multivariate analysis (Table 4). Multivariate analysis showed that other than age, duration of diabetes and $\mathrm{HbA}_{1 \mathrm{c}}$, weight, current smoking, severe ketoacidosis, macroalbuminuria, background and proliferative retinopathy were found to be independent risk factors for neuropathy. When the analysis was repeated to include serum triglyceride level using fasting patients only, independent risk factors for neuropathy were age, duration of diabetes, $\mathrm{HbA}_{1 \mathrm{c}}$, height, severe ketoacidosis, background and proliferative retinopathy and serum triglyceride level.

\section{Discussion}

The neurological analysis of subjects in the EURODIAB study represents one of the largest bodies of data concerning IDDM. It must be stressed that this study used subjects selected from well-established hospital-based diabetes clinics and gives no information concerning people in the wider community and those with non-insulin-dependent diabetes. The methodology for defining diabetic neuropathy in this study is very close to other protocols $[4,5,9]$ which attempt 


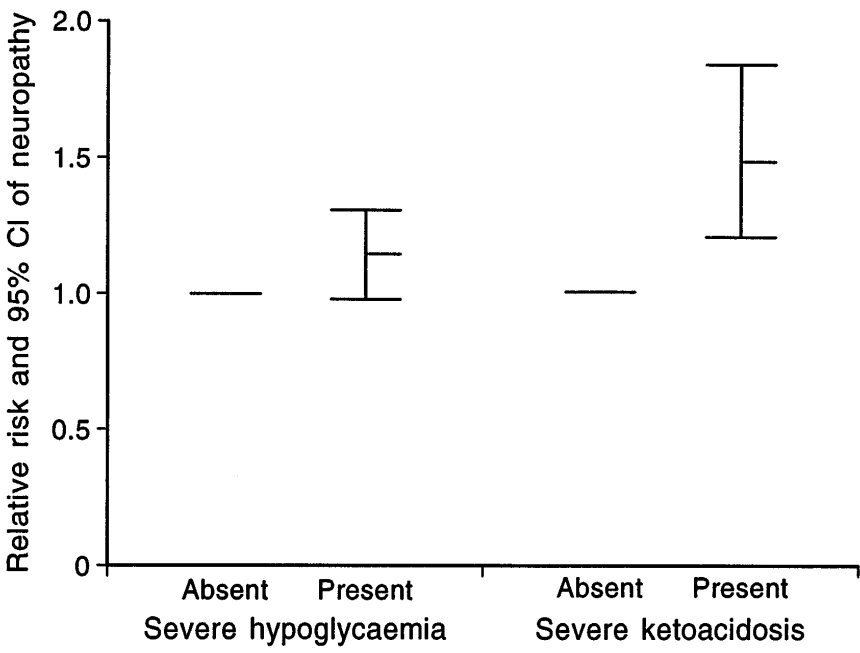

Fig. 2. Relative risk of neuropathy associated with acute diabetic complications

to standardise the definition and it is suggested that since the described protocol in this EURODIAB IDDM Complications Study has been used around Europe, this could be taken as a reasonable standard for epidemiological European studies in the future.

Using the definition of diabetic neuropathy described in the Methods section, $28 \%$ of subjects have neuropathy, a frequency similar to that found in other studies $[2,4,9]$, suggesting that neurological assessment in such protocols has become fairly well standardised. Even in some recent population-based studies [14-17], the reported prevalence rates for neuropathy are similar to those in the present study. One such study reported that about $20 \%$ of diabetic patients had symptomatic neuropathy; however, about $50 \%$ were found to have objective evidence of diabetic polyneuropathy [17]. Our results confirm the well-established correlations between the prevalence of neuropathy and age [9, 18-20], duration of diabetes [9, 18-21], and metabolic control [9, 20, 21]. Significant associations have also been reported with height $[5,22,23]$, cigarette smoking [9], the presence of retinopathy $[9,21]$, both background

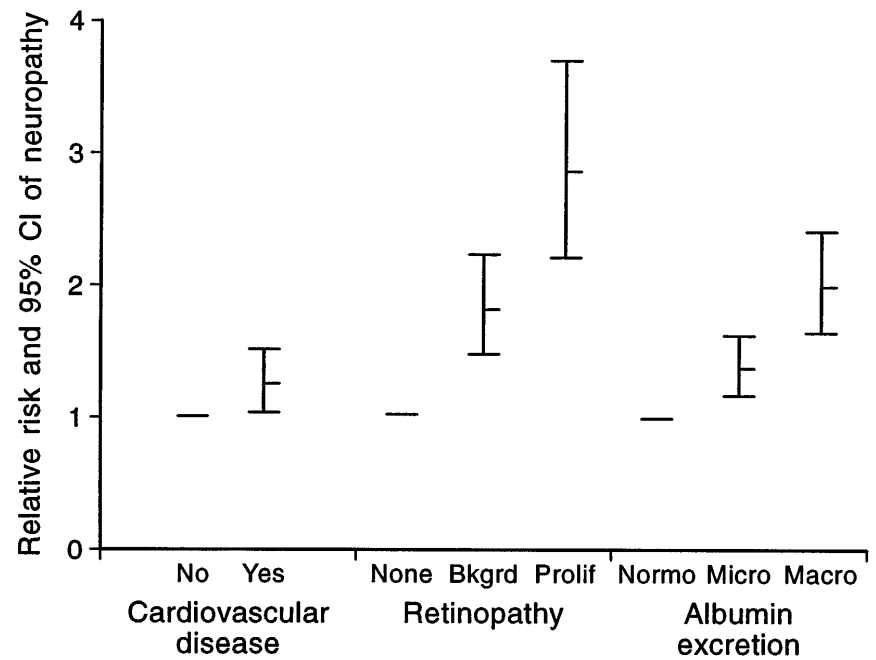

Fig. 3. Relative risk of neuropathy associated with chronic diabetic complications. Bkgrd, Background; Prolif, proliferative

and proliferative, and reduced levels of HDL-cholesterol [9].

However, some new associations of interest have been identified. The association with microalbuminuria is of potential importance and has not been previously described. This of course may simply reflect a general association with advanced disease. On the other hand it may be used to support the microvascular hypothesis in the pathogenesis of diabetic neuropathy [24-28] in that microalbuminuria, as a marker for early nephropathy, has undoubted microvascular aetiology. Moreover, there has recently been interest in the observation that the state of the autonomic nervous system relates to renal dysfunction, and it has been suggested that this could be due to autonomic neuropathy-induced impairment of renal blood flow $[29,30]$. This observation is interesting and merits further research.

The strong association observed between neuropathy and severe ketoacidosis has also not been previously described. This may provide further evidence for the role of microvascular damage in the pathogenesis of neuropathy. It is known that severe

Table 4. Multiple logistic regression analysis of risk factors for diabetic neuropathy

\begin{tabular}{|c|c|c|c|c|c|c|c|}
\hline \multirow[t]{2}{*}{ Risk factor } & \multicolumn{3}{|c|}{ Excluding fasting triglyceride from the model } & \multirow[t]{2}{*}{ Risk factor } & \multicolumn{3}{|c|}{ Including triglyceride in the model } \\
\hline & $\begin{array}{l}\text { Standardised } \\
\text { relative risk }\end{array}$ & $(95 \% \mathrm{CI})$ & $p$-value & & $\begin{array}{l}\text { Standardised } \\
\text { relative risk }\end{array}$ & $(95 \% \mathrm{CI})$ & $p$-value \\
\hline Duration of diabetes & 1.3 & $(1.1,1.6)$ & 0.0005 & Duration of diabetes & 1.4 & $(1.1,1.8)$ & 0.007 \\
\hline $\mathrm{HbA}_{1 \mathrm{c}}$ & 1.6 & $(1.4,1.9)$ & 0.0001 & $\mathrm{HbA}_{1 \mathrm{c}}$ & 1.5 & $(1.3,1.8)$ & 0.0001 \\
\hline Weight & 1.2 & $(1.0,1,4)$ & 0.008 & Height & 1.3 & $(1.1,1.5)$ & 0.007 \\
\hline Current smoking & 2.4 & $(1.1,5.0)$ & 0.02 & Severe ketoacidosis & 3.0 & $(1.6,5.7)$ & 0.0007 \\
\hline Background retinopathy & 2.0 & $(1.5,2.8)$ & 0.001 & Fasting triglyceride $^{\mathrm{a}}$ & 1.3 & $(1.1,1.5)$ & 0.009 \\
\hline Proliferative retinopathy & 5.4 & $(3.4,8.6)$ & 0.001 & & & & \\
\hline
\end{tabular}

\footnotetext{
${ }^{a}$ Logged variable
} 
microvascular abnormalities occur in the brain and peripheral nerves of those dying in diabetic ketoacidosis [31]. This consists primarily of disseminated intravascular coagulation with the deposition of coagulation breakdown products within the vessel lumen and the presence of layering of fibrin on the endothelial surface with, at times, disruption and exudation into the vessel wall itself. One therefore speculates whether the thickened layered appearance of the sural nerve capillary in neuropathy [32] is related to successive "intravascular insults" occurring during episodes of poor metabolic control.

Since all these associations have been adjusted for age, duration of diabetes and metabolic control, a reduced level of HDL-cholesterol and an elevated level of fasting triglyceride level in association with neuropathy is of interest. Schwann cell lipid metabolism has been found to be abnormal [33], and as a previous study has also reported a significant association of diabetic neuropathy with lower HDL-cholesterol levels [9], this may reflect a blood marker of the pathological changes in the myelin structure of nerve. The significant association observed between neuropathy and cigarette smoking may at least in part be secondary to the vascular effects of the latter, as there has been increasing evidence of the importance of microvascular factors in the pathogenesis of diabetic neuropathy [24-28].

Estimates of peripheral nerve dysfunction in the EURODIAB IDDM Complications Study should contribute to the understanding of the pathogenesis of diabetic neuropathy. The strong association of neuropathy with retinopathy, microalbuminuria and macroalbuminuria might be seen to lend support to the microvascular hypothesis [24]. The marked increase in the prevalence of neuropathy in a few centres compared to the majority was mainly felt to be due to variations in the technique of neurological and neurophysiological examination, although centrally calibrated biothesiometers were used and an attempt was made to standardise the method of autonomic function testing by visiting all the participating centres. It is also possible that differences in the referral pattern of diabetic patients to hospital-based specialists may be another factor, in that while in some countries all patients with IDDM are followed at hospitals, in other countries only those who can afford it or those with complications are followed in hospitals. However, there was remarkable similarity in the prevalence of neuropathy between most centres, and indeed with other previous studies. In some ways it was disappointing that no geographical differences were observed, for this might have led to identification of environmental factors likely to be associated with nerve damage. The various associations reported in the present study were reproduced when either abnormal vibration perception threshold alone or both abnormal vibration perception threshold and autonomic dysfunction were used to define the presence of neuropathy, but not when autonomic dysfunction was used as the sole criterion for the presence of peripheral neuropathy.

The role of alcohol in the development of diabetic neuropathy has been questioned for many decades. The association of leg-reflex change and autonomic dysfunction with alcohol consumption in the absence of overall association with total neuropathy score does not allow any useful conclusion. As ever, the unreliability of self-reporting of alcohol intake over a short period of time may well be the major reason for lack of a significant association.

The range of responses given to our various questions regarding impotence varied enormously among centres, from 2 to $85 \%$. The similarity of patterns of answers in some centres suggests that cultural and personal attitudes did not allow patients and their doctors to communicate in such a way that the true prevalence could be ascertained. This might indicate that in some centres it is not possible for patients with impotence to discuss their problem, and hence they will not be offered help or treatment. Strategies should therefore be developed to allow all men with diabetic impotence and their partners to raise this topic and receive help. For the future, studies of a fundamental nature will be required to allow an understanding of the pathogenesis of diabetic neuropathy. However, this large study has identified important potential risk factors for diabetic neuropathy. Examination of these patients in the future may lead to identification of factors which have led to the development of neuropathy or the progress of established neuropathy. This is clearly important, as risk reduction strategies may then be developed [9].

Acknowledgements. We thank all the patients who took part in the study. The study was part of the EURODIAB Concerted Action Programme financially supported by the Commission of the European Communities. Additional financial support was received from ICI UK, Fidia, Bayer, Miles-Ames, Novo Nordisk and Pfizer.

\section{EURODIAB investigators}

B. Karamanos, C.Tountas, A.Kofinis, K.Petrou, N. Katsilambros, Hippokration Hospital, Athens, Greece

R. Giorgino, M. Cignarelli, M. L. De Cicco, I. Ramunni, Istituto di Clinica Medica, Endocrinologia e Malattie Metaboliche, Università di Bari, Bari, Italy

C.Ionescu-Tirgoviste, C.M.Iosif, D. Pitei, S.Buligescu, Clinic of Diabetes, Nutrition and Metabolic Diseases, Bucharest, Romania

G. Tamas, Z. Kerenyi, A. M. Ahmed, J. Toth, P. Kempler, Tetenyi Teaching Hospital and Semmelweis University, Budapest, Hungary

Se.Muntoni, M.Songini ${ }^{a}$, M.Stabilini, M.Fossarello ${ }^{\text {a }}$, S.Pintus $^{\mathrm{a}}$, Sa. Muntoni, Centro Malattie Dismetaboliche and ${ }^{\mathrm{a}}$ Ospedale San Michele, Cagliari, Italy 
J.B.Ferriss, C.C.Cronin, A.E. Whyte, P.E.Cleary, Cork Regional Hospital, Cork, Ireland

M.Toeller, A.Klischan, T.Forst, F.A.Gries, Diabetes Forschungsinstitut, Universität Düsseldorf, Germany

R. Rottiers, H.Priem, University Hospital of Gent, Belgium

P. Ebeling, M.Sinisalo, V.A. Koivisto, University Hospital of Helsinki, Finland

B. Idzior-Walus, B. Solnica, L. Szopinska-Ciba, K. Solnica, University School of Medicine, Krakow, Poland

H.M.J.Krans, H.H. P.J.Lemkes, J.J.Jansen, J. Brachter, University Hospital of Leiden, The Netherlands

J. Nunes-Correa, J. Boavida, Portuguese Diabetic Association, Lisbon, Portugal

G. Michel, R. Wirion, Centre Hospitalier, Luxembourg

A.J.M.Boulton, H. Ashe, D. J.S. Fernando, Manchester Royal Infirmary, UK

G. Pozza, G. Slaviero, G. Comi, B. Fattor, F. Bandello, Ospedale San Raffaele, Milan, Italy

H.U.Janka, A.Nuber, H.Mehnert, City Hospital Schwabing, Munich, Germany

D. Ben Soussan, M.-C.Fallas, P.Fallas, Centre Hospitalier de Valenciennes, France

E.Jepson, S.McHardy-Young, Central Middlesex Hospital, and J.H.Fuller, D. J.Betteridge, M. Milne, University College Hospital, NW London

G. Crepaldi, R. Nosadini, T. Segato, E. Midena, M. R. Cipollina, D. Fedele, Instituto di Medicina Interna, Padua, Italy

G. Cathelineau, B. Villatte Cathelineau, M.Jellal, N. Grodner, P. Gervais Feiss, Hospital Saint-Louis, Paris, France

F. Santeusanio, G. Rosi, M. R. M. Ventura, C. Cagini, C. Marino, Instituto di Pathologia Medica, Policlinico, Perugia, Italy

R. Navalesi, A. Plaggesi, E. Castro Lopez, G. Penno, R. Miccoli, Instituto di Clinica Medica II, Pisa, Italy

G. Ghirlanda, P. Cotroneo, A. Manto, C. Teodonio, A. Minnella, Universita Cattolica del Sacro Cuore, Rome, Italy

J.D. Ward, S. Tesfaye, C.Mody, C.Rudd, Royal Hallamshire Hospital, Sheffield, UK

G. M. Molinatti，F. Vitelli， M. Porta, G.F.Pagano, P.Cavallo Perin, P.Estivi, R. Sivieri, Q. Carta, G. Petraroli, Clinica Medica B, Patologia Medica, Ospedale Molinette, and Ospedale "Agnelli", Turin, Italy

N.Papazoglou, G. Manes, G. Triantaphyllou, A.Ioannides, G. Skazagar, I. Kontogiannis, General Hospital of Thessaloniki, Greece

M. Muggeo, V. Cacciatori, F. Bellavere, P. Galante, M. L. Gemma, Cattedra di Malattie del Metabolismo, Verona, Italy

K. Irsigler, H. Abrahamian, C. Gurdet, B.Hornlein, C. Willinger, Hospital Vienna Lainz, Austria

S. Walford, E. V.Wardle, S.Hughes, New Cross Hospital, Wolverhampton, UK

G. Roglic, Z. Resman, Z.Metelko, Z.Skrabalo, Vuk Vrhovac Institute for Diabetes, Zagreb, Croatia

Steering Committee Members: J.H.Fuller (London), H. Keen, Chairman (London), H.M.J.Krans (Leiden), R. Navelesi (Pisa), A.-K.Sjolie (Aarhus), J.M.Stephenson (London), M. Toeller (Düsseldorf), G.-C. Viberti (London), J. Ward (Sheffield)

Co-ordinating Centre: J.H.Fuller, J.Stephenson, T.Partridge, M. Milne, UCL Medical School, UK

Central Laboratories: G.John, The Royal London Hospital, and G.-C. Viberti, M. Mattock, A.Collins, A. Dredge, R. Sharp, Guy's Hospital, London, UK

Retinopathy Co-ordination: A.-K.Sjolie, Aarhus University Hospital, Denmark

Retinopathy Grading Centre: E.Kohner, S.Aldington, S. Cockley, Hammersmith Hospital, London, UK

\section{References}

1. Ward JD (1982) The diabetic leg. Diabetologia 22: 141-147

2. Ziegler D, Gries FA, Spuler M, Lessmann F and the DiaCAN Multicentre Study Group (1993) The epidemiology of diabetic neuropathy. Diabet Med 10 [Suppl 2]: 82S-86S

3. Goodman JL, Baumoel S, Frankel L, Markus LJ, Wasserman S (1953) The diabetic neuropathies. CC Thomas Springfield, Illinois, pp 1-66

4. Young MJ, Boulton AJM, Macleod AF, Williams DRR, Sonksen PH (1993) A multicentre study of the prevalence of diabetic peripheral neuropathy in the United Kingdom hospital clinic population. Diabetologia 36: 150-154

5. The DCCT Research Group (1988) Factors in the development of diabetic neuropathy. Diabetes 37: 476-481

6. Consensus Statement (1988) Report and recommendations of the San Antonio Conference on diabetic neuropathy. Diabetes Care 37; 1000-1004

7. The EURODIAB IDDM Complications Study Group (1994) Microvascular and acute complications in IDDM patients: the EURODIAB IDDM Complications Study. Diabetologia 37: 278-285

8. Aldington SJ, Kohner EM, Meuer S, Klein R, Sjolie AK for the EURODIAB IDDM Complications Study Group (1995) Methodology for retinal photography and assessment of diabetic retinopathy: the EURODIAB IDDM Complications Study. Diabetologia 38: 437-444

9. Maser RE, Steenkiste AR, Dorman JS et al. (1989) Epidemiological correlates of diabetic neuropathy. Report from Pittsburgh Epidemiology of Diabetes Complications Study. Diabetes 38: 1456-1461

10. Ward JD (1994) Diabetic neuropathy. In: Williams R, Papoz L, Fuller JH (eds) Diabetes in Europe. John Libbey and Company Ltd/Editions INSERM, pp 72-77

11. Bloom S, Till S, Sonksen P, Smith S (1984) Use of biothesiometer to measure individual vibration thresholds and their variation in 519 non-diabetic subjects. BMJ 288: 1793-1795

12. Wiles PG, Pearce SM, Rice PJS, Mitchell JMO (1991) Vibration perception threshold: influence of age, height, sex and smoking, and calculation of accurate centile values. Diabet Med 8: 157-161

13. Ewing DJ, Martyn CN, Young RJ, Clarke BF (1985) The value of cardiovascular autonomic function tests: 10 years experience in diabetes. Diabetes Care 8: 491-498

14. Ziegler D (1994) Diagnosis, staging and epidemiology of diabetic peripheral neuropathy. Diab Nutr Metab 7: 342348

15. Veglio M, Sivieri R, The Neuropathy Study Group of the Italian Society for the Study of Diabetes, Piemonte affiliate (1993) Prevalence of neuropathy in IDDM patients in Piemonte, Italy. Diabetes Care 16: 456-461

16. Harris M, Eastman R, Cowie C (1993) Symptoms of sensory neuropathy in adults with NIDDM in the US population. Diabetes Care 16: 1446-1452

17. Dyck PJ, Kratz KM, Karnes JL et al. (1993) The prevalence by staged severity of various types of diabetic neuropathy, retinopathy, and nephropathy in a population based cohort: The Rochester Diabetic Neuropathy Study. Neurology 43: 817-824

18. Boulton AJM, Knight G, Drury J, Ward JD (1985) The prevalence of symptomatic diabetic neuropathy in an insulin-treated population. Diabetes Care 8: 125-128

19. Knuiman MW, Welborn TA, McCann VJ, Stanton KG, Constable IJ (1986) Prevalence of diabetic complications in relation to risk factors. Diabetes 35: 1332-1339 
20. Franklin GM, Kahn LB, Baxter J, Marshall JA, Hamman RF (1990) Sensory neuropathy in non-insulin-dependent diabetes mellitus. The San Luis Valley Diabetes Study. Am J Epidemiol 131: 633-643

21. Pirart J (1978) Diabetes mellitus and its degenerative complications: a prospective study of 4400 patients observed between 1947 and 1973. Diabetes Care 1: 168-188 and 252-263

22. Hyllienmark L, Brismar T, Ludvigsson (1995) Subclinical nerve dysfunction in children and adolescents with IDDM. Diabetologia 38: 685-692

23. Sosenko JM, Gadia MT, Fournier AM, O'Connell MT, Aguiar MC, Skyler JS (1986) Body stature as a risk factor for diabetic sensory neuropathy. Am J Med 80: 10311034

24. Tesfaye S, Malik R, Ward JD (1994) Vascular factors in diabetic neuropathy. Diabetologia 37: 847-854

25. Tesfaye S, Harris N, Jakubowski J et al. (1993) Impaired blood flow and arterio-venous shunting in human diabetic neuropathy: a novel technique of nerve photography and fluorescein angiography. Diabetologia 36: 1266-1274

26. Tesfaye S, Harris N, Wilson RM, Ward JD (1992) Exercise induced conduction velocity increment: a marker of impaired nerve blood flow in diabetic neuropathy. Diabetologia 35: 155-159
27. Tesfaye S, Malik R, Harris N et al. (1996) Arterio-venous shunting and proliferating new vessels in acute painful neuropathy of rapid glycaemic control (insulin neuritis). Diabetologia 39: 329-335

28. Cameron NE, Cotter MA, Low PA (1991) Nerve blood flow in early experimental diabetes in rats: relation to conduction deficits. Am J Physiol 261: E1-E8

29. Spallone V, Gambardella S, Maiello MR, Barini A, Frontoni S, Menzinger G (1994) Relationship between autonomic neuropathy, 24-h blood pressure profile, and nephropathy in normotensive IDDM patients. Diabetes Care 17: 578584

30. Sundkvist G, Lilja B (1993) Autonomic neuropathy predicts deterioration in glomerular filtration rate in patients with IDDM. Diabetes Care 16: 773-779

31. Timperley WR, Preston FE, Ward JD (1974) Cerebral intravascular coagulation in diabetic ketoacidocis. Lancet i: 952-956

32. Malik RA, Newrick PJ, Sharma AK et al. (1989) Microangiopathy in human diabetic neuropathy: relationship between capillary abnormalities and severity of neuropathy. Diabetologia 32: 92-102

33. Thomas PK, Ward JD, Watkins PJ (1982) Diabetic neuropathy. In: Keen H, Jarrett J (eds) Complications of diabetes. Arnold, London, pp 109-136 